\title{
Pharmacological activities of a novel plant species, Huernia Sp. Nov. aff. Boleana growing in the high mountains of southwest Saudi Arabia
}

\author{
FAYEZ HAMAM $^{1}$, AHMED ELDALO ${ }^{1}$, QASEM ABDALLAH ${ }^{1}$, \\ IBRAHIM AL-DEEB ${ }^{1}$, SALEH ALZAHRANI ${ }^{2}$, ABDULLAH ALWAGDANI ${ }^{2}$, \\ AHMED ALOTAIBI $^{2}$, ABDEL-RAHMAN NASR $^{1}$, YASER GOUDA ${ }^{3,4}$ and KHALED MOHAMED ${ }^{4}$ \\ Departments of ${ }^{1}$ Pharmacology and Toxicology, ${ }^{2}$ Clinical Pharmacy and \\ ${ }^{3}$ Pharmacognosy, College of Pharmacy, Taif University, Taif, Makkah 21974, Kingdom of Saudi Arabia; \\ ${ }^{4}$ Department of Pharmacognosy, Faculty of Pharmacy, Assiut University, Assiut 71526, Egypt
}

Received October 29, 2017; Accepted January 5, 2018

DOI: $10.3892 / \mathrm{mmr} .2018 .8607$

\begin{abstract}
Huernia Sp. Nov. aff. Boleana, Apocynaceae, grows in the high mountains of southwest Saudi Arabia and is widely used as a remedy for the treatment of diabetes. The present study investigated the anti-inflammatory, wound healing and inhibitory effects on migration of Huernia Sp. Nov. aff. Boleana. The anti-inflammatory effect was assessed in mice using formalin-induced edema. Wound healing effects were assessed in rats using a circular excision wound model. An in vitro 'scratch' test was used to investigate the inhibitory effects on melanoma cell (B16-F10) migration. The anti-inflammatory effects of total extract, hexane and chloroform fractions were greater or equal to indomethacin (control). The relatively non-polar fractions (hexane and chloroform) exhibited higher anti-inflammatory activities compared with the aqueous fraction. The percentage of wound contraction among animals treated with the plant extract was higher compared with the control; however, this difference was not statistically significant $(\mathrm{P}>0.05)$. The total plant extract increased wound healing by inhibiting the inflammatory response, promoting angiogenesis, and significantly promoting the proliferation of fibroblasts, particularly on days 7 and 14 post-wounding. Furthermore, the plant extract promoted wound repair via the enhancement of collagen synthesis, and complete epithelization with well-formed and differentiated epithelial tissues. The in vitro 'scratch' test indicated the inhibitory effects of this plant on melanoma cell migration in a dose-dependent manner. The present study indicated that Huernia Sp.Nov. aff. Boleana
\end{abstract}

Correspondence to: Dr Fayez Hamam, Department of Pharmacology and Toxicology, College of Pharmacy, Taif University, 2657 Airport Road, Taif, Makkah 21974, Kingdom of Saudi Arabia E-mail: f.hamam@tu.edu.sa

Key words: woundhealing, anti-inflammatory, Huernia Sp. Nov. aff. Boleana, scratch test may have potential as an anti-inflammatory, wound-healing and migration-inhibiting ethno medicine.

\section{Introduction}

Huernia Sp. Nov. aff. Boleana is a wild plant taxonomically belonging to the family Apocynaceae, which has $\sim 348$ genera and $\sim 2,900$ species. This plant has attracted attention due to its wide use in the western and southwestern regions of Saudi Arabia in traditional medicines, particularly in the treatment of diabetes. Numerous databases have indicated that only two studies have reported the role of this plant as a pharmacologically-active agent. For example, Alzahrani et al (1) investigated the antidiabetic activity of this plant; chloroform and total methanol extracts of Huernia Sp. Nov. aff. Boleana demonstrated a considerable effect in lowering blood glucose in streptozotocin-induced diabetic mice compared with control animals. Almehdar et al (2) investigated, in vitro, the cytotoxic effect of Huernia Sp. Nov. aff. Boleana Gilb using three tumor cell lines, notably breast cancer (MCF7), cervical cancer (HeLa) and liver cancer (HEPG2) cells, and reported that the tested plant exhibited poor anticancer activity against the aforementioned cells.

Inflammation may be considered to be part of a complex biological response of the vascular system to noxious stimuli, including pathogens, irritants and damaged cells. It is a protective mechanism used by the body to eliminate the harmful stimuli and to initiate the process of healing. Inflammation has attracted great attention due to its involvement in human and animal disorders. The traditional therapeutic agents used to modify inflammation are too costly or toxic, and less available to those inhabiting rural areas, constituting a large proportion of the global population. Furthermore, the non steroidal anti-inflammatory drugs used for treatment of symptomatic inflammation may cause numerous side effects, including stomach intolerance, retention of water and electrolytes, depression of bone marrow and increased risk of cardiovascular diseases (3). Thus, the search for natural anti-inflammatory agents with no or minimal side effects is urgent. 
Natural wound healing is a complex and dynamic process which may be divided into four overlapping, although well-defined, stages, namely homeostasis, inflammation, proliferation (consisting of tissue formation, contraction and re-epithelization) and tissue remodeling, which establishes the strength and appearance of the healed area (4). Wound healing involves complex interactions between extracellular matrix components, soluble mediators, a variety of resident cells, and infiltrating polymorpho nuclear and mononuclear leukocytes. The immediate objective in the process of wound healing is to restore integrity of injured tissues and homeostasis (5). The inflammatory stage involves the infiltration of blood cells, notably neutrophils and monocytes to the injured site (6). The migration of phagocytic neutrophils and macrophages initially eliminates foreign particles and releases cytokines. Despite widespread traditional use of this plant, to the best of our knowledge, no scientific study has been performed to investigate its potential as an anti-inflammatory and wound-healing agent.

\section{Materials and methods}

Plant materials. Huernia Sp. Nov. aff. Boleana was collected from Rusaba (20.121736 and 41.347589), which is located in the Southwestern region of the Kingdom of Saudi Arabia (KSA). Identification of the plant was performed by Dr. Yassin M. Al-Sodany of the Department of Botany, College of Science, Taif University, Taif, KSA. A voucher specimen of the plant was kept at the Herbarium in the Department of Pharmacognosy, College of Pharmacy, Taif University.

Preparation of plant extracts. The plant was allowed to air dry, and $480 \mathrm{~g}$ of the air-dried materialwas powdered and treated with methanol $(99.8 \%)$ at $60^{\circ} \mathrm{C}$ for $24 \mathrm{~h}$ for extraction until exhaustion. The methanol was evaporated under vacuum (337 mbar) at $40^{\circ} \mathrm{C}$ and $50 \mathrm{rpm}$ using a rotary evaporator (RE100-Pro; Dragon Lab, Beijing, China) and 87 g grams dried total methanolic extract was obtained. The total methanol (47 g) was reconstituted in distilled water $(10 \mathrm{ml})$. Successive fractionation was conducted with chloroform followed by n-hexane. The chloroform fraction produced $23.8 \mathrm{~g}$, while the $\mathrm{n}$-hexane fraction from the total methanol extract provided $3.4 \mathrm{~g}$. Lyophilization of the aqueous fraction was performed at $-20^{\circ} \mathrm{C}$ overnight and $16.4 \mathrm{~g}$ was obtained. All fractions (n-hexane, chloroform and aqueous) were stored at $-20^{\circ} \mathrm{C}$ until further analysis.

Anti-inflammatory study, animals. A total of $30 \mathrm{Balb} / \mathrm{c}$ female mice (25-30 g; 8-10 weeks) were obtained from the animal house of King Abdul-Aziz University (Jeddah, Kingdom of Saudi Arabia). The animals were allowed to acclimatize for two weeks following transportation. Animals were divided into six groups, each constituting five mice. The animals were housed at $25 \pm 2^{\circ} \mathrm{C}, 12 \mathrm{~h} \mathrm{light/dark}$ cycle and a relative humidity of $60 \pm 5 \%$. All animals were deprived of food and water for $18 \mathrm{~h}$ prior to experimentation. Group 1 (negative control) received distilled water orally, group 2 (positive control) received an oral dose of indomethacin $(10 \mathrm{mg} / \mathrm{kg})$, and experimental groups 3-6 were administered oral doses of $500 \mathrm{mg} / \mathrm{kg}$ total extract (TE), hexane, chloroform and aqueous fractions, respectively. The present study was approved by the Medical Ethical Committee at the Department of Pharmacology and Toxicology, College of Pharmacy, Taif University (2017/TU/Pharmacy/01), and followed the ethical guidelines EEC999 (European Union, 1982).

The tail of each mouse was marked $\sim 0.5 \mathrm{~cm}$ from its base. A plethysmometer (Ugo Basil S.R.L, Comerio, VA, Italy) was used to measure the tail volume up to the mark. Following oral administration of the drugs and various plant fractions, the animals were maintained for $60 \mathrm{~min}$ prior to inflammatory induction, which was performed via an injection of $100 \mu \mathrm{l}$ formalin solution. The volume (Vf) displacement method was employed for the determination of the tail volume. This method based on measuring tail volume prior to and following induction of inflammation or edema. The tail volume (Vi) prior to induction of edema was measured by dipping the tail in the bath using a Digital plethysmometer. Measurement was performed at 1,2, 3 and $4 \mathrm{~h}$ post-inflammatory induction in order to obtain the final tail volume (Vf). The percentage alteration in tail volume from the initial volume was determined via application of the following equation: Percent change $=[(\mathrm{Vf}-\mathrm{Vi}) / \mathrm{Vi}] \times 100$, where Vf stands for final tail volume and Vi stands for initial tail volume.

Wound healing. Male Wistar rats (16) weighing 200-250 g and aged 8-10 weeks were obtained from the animal house of King Abdul-Aziz University (Jeddah, Kingdom of Saudi Arabia). The animals were allowed to acclimatize for two weeks following transportation. The animals were housed at $25 \pm 2{ }^{\circ} \mathrm{C}, 12 \mathrm{~h} \mathrm{light/dark}$ cycle and a relative humidity of $60 \pm 5 \%$. The animals were supplied with water and standard feed pellets. The rats were divided into two groups of nine each. Group1 (control) received topical application of the standard drug (sulphadiazane, commercially known as Flamazine; Riyadh Pharma, Riyadh, Kingdom of Saudi Arabia). Group 2 were treated with $1 \%$ TE of Huernia Sp. Nov. aff. Boleana in a carbopol 934 gel $(1 \%$, w/w). Rats were anesthetized using $0.8 \mathrm{ml}$ choral hydrate $(400 \mathrm{mg} / \mathrm{kg})$, the dorsal region was shaved, and a circular excision of $\sim 25 \mathrm{~mm}$ diameter (calculated area ranged from 400-450 $\mathrm{mm}^{2}$ ) was performed in the dorsal area of each rat. Topical treatments were performed twice per day for 20 days, the first time at 9:00 a.m. and the second time at 3:00 p.m. Measurement of the diameter was performed using a digital caliper on day 3, $6,9,12,15,18$ and 21 . On day 7 post-wounding, three animals were selected randomly from each group and were sacrificed. A cross-sectional skin specimen of the excision wound was obtained for histological study. On day 14 post-wounding, a further three animals from each group were sacrificed and a skin specimen of the excision wound was collected, as performed on day 21 post-wounding. The remaining animals were sacrificed and skin specimens were collected and fixed in $10 \%$ formalin at room temperature for $24 \mathrm{~h}$ for further histological investigation.

Percentage wound contraction was determined by applying the following equation: percentage wound contraction=(initial wound size-specific day wound size)/initial wound size) x100.

Histological study. Collected specimens were fixed in $10 \%$ formalin at room temperature for $24 \mathrm{~h}$, embedded in 
paraffin and sectioned using a microtome (SLEE medical $\mathrm{GmbH}$, Mainz, Germany) into 5- $\mu \mathrm{m}$ sections. Sectioned specimens were processed using a standard procedure (7) and stained using hematoxylin and eosin (H\&E). Although Masson's Trichrome is better suited for distinguishing cells from surrounding connective tissue compared with $\mathrm{H} \& \mathrm{E}$, Masson's Trichrome staining was unavailable during the course of the present study. The stained specimens were mounted in DPX (Sigma-Aldrich; Merck KGaA, Darmstadt, Germany) and examined under a light microscope (magnification, x10-40) for any histological alterations, including inflammation, new vascularization (angiogenesis), fibroblast proliferation, the presence of collagen and re-epithelization. Testing of the specimens from the experimental group was performed in a blinded manner and outcomes were compared with those specimens treated with sulphadiazine (control group).

In vitro scratch method for analysis of melanoma cells (B16-F10) migration. B16-F10 cell line was kindly provided by Dr. Amin Abdul Majid (Department of Pharmacology and Toxicology, School of Pharmaceutical Sciences, University Sains Malaysia, Pulau Pinang, Malaysia). The cells were cultured in Dulbecco's modified Eagle's medium (DMEM; Gibco; Thermo Fisher Scientific, Inc., Waltham, MA, USA) supplemented with $10 \%$ fetal bovine serum (Gibco; Thermo Fisher Scientific, Inc.), $1 \mathrm{mM}$ sodium pyruvate and $2 \mathrm{mM}$ L-glutamine for $48 \mathrm{~h}$ in a humidified incubator at $37^{\circ} \mathrm{C}$ and $5 \% \mathrm{CO}_{2}$. The scratch method is easy and inexpensive, and it is used to simulate cell migration during the course of wound repair in vivo (8). The basic steps include making an artificial gap 'scratch' on a confluent monolayer of cells; the cells on the edge of the scratch travel toward the gap in order to close the scratch. Cell movements will continue until cell-cell contacts are reached. Images may be captured at the start and at regular time intervals (e.g., 12 and $24 \mathrm{~h}$ ) during cell migration, and the final step involves comparing the images captured to determine cells migration rate (7). A total of $2 \mathrm{ml}$ DMEM culture medium containing B16-F10 cells at a density of $2 \times 10^{5}$ cells $/ \mathrm{ml}$ was pipetted into each well of a 6 -well plate. The plate was incubated for $48 \mathrm{~h}$ in a humidified incubator at $37^{\circ} \mathrm{C}$ and $5 \% \mathrm{CO}_{2}$ to achieve absolute confluent monolayer cells. Subsequently, the middle of the monolayer was scraped to create a straight-line scratch using the sterile tip of a $200-\mu 1$ pipette; the scratches were of a similar size to minimize any variation due to scratch width. The medium was discarded carefully and the plate was rinsed twice with PBS to remove the debris. The consumed medium was replenished with fresh DMEM containing the plant extract at a concentration of 100 and $200 \mu \mathrm{g} / \mathrm{ml}$, while the control cells were treated with dimethyl sulfoxide (DMSO; $0.1 \%$ in DMEM). Subsequently, numerous images were acquired of the wounds at the beginning of the experiment $(0 \mathrm{~h})$ using an inverted light microscope at a magnification of $\mathrm{x} 10$, and the plate was re-incubated at $37^{\circ} \mathrm{C}$ and $5 \% \mathrm{CO}_{2}$ for 12 and $24 \mathrm{~h}$. Microscopic observations at regular intervals (at 0, 12 and $24 \mathrm{~h}$ ) were performed for cell migration analysis. Following 12 and $24 \mathrm{~h}$ of incubation, images acquired for each treatment were analyzed using ImageJ1.51n ${ }^{\circledR}$ (National Institutes of Health, Bethesda, MD, USA) software. For each image acquired, the distance $(\mu \mathrm{m})$ between one side of the scratch and the other side was determined at certain intervals (at 0 , 12 and $24 \mathrm{~h}$ ). The distance traveled by cells on the edge of the gap toward the opening in order to close the scratch was determined by comparing the images acquired at time $0 \mathrm{~h}$ to those captured at 12 and $24 \mathrm{~h}$.

The resulting distances were reported as the percentage of inhibition of migration compared with the mean distance for the negative control; it was calculated using the following formula: \% of inhibition of migration $=[1-(\mathrm{Ds} / \mathrm{Dc})] \mathrm{x} 100$, where Ds, distance travelled by cells treated with extract; Dc, distance travelled by cells treated with DMSO.

Statistical analysis. One-way analysis of variance was used to compare between the six groups. Since there was a significant difference, the Tukey post hoc test was used to make pairwise comparisons among the six groups to identify where the difference lay. Statistical analysis was performed using SPSS 22.0 (IBM Corp., Armonk, NY, USA). The significance of the differences was determined at a $95 \%$ confidence interval and $\mathrm{P}<0.05$ was considered to indicate a statistically significant difference. Data were presented as the mean \pm standard deviation. The number of replicates $(n)=5$ for anti-inflammatory assays and $n=9$ for wound healing assays.

\section{Results}

Anti-inflammatory study. As presented in Fig. 1A, the percentage alterationin tail volume following $1 \mathrm{~h}$ of induction of inflammation was analyzed. The anti-inflammatory effects (as indicated by the percentage alteration in tail size) of the TE, hexane and chloroform fractions were better or equivalent compared with the effect of indomethacin (positive control); however, this effect was not statistically significant. The lowest efficacy was noted among animals treated with the aqueous fraction. The TE, hexane and chloroform fractions exhibited anti-inflammatory effects similar to the effect of indomethacin at $2 \mathrm{~h}$, although this effect was not significant (Fig. 1B). This pattern was similar to that noted following $1 \mathrm{~h}$ of inflammation induction. However, animals that received the TE, hexane and chloroform fractions exhibited a significant percentage alteration in tail size compared with their counterparts in the negative group. Additionally, the aqueous extract demonstrated marginal effects on tail volume, as no significant difference was noted compared with the negative control (Fig. 1B).

The percentage alteration $(36.8 \%)$ in tail volume was determined in hexane-treated animals, followed by those receiving TE (38.4\%) at $3 \mathrm{~h}$ (Fig. 1C). However, this effect was not significant compared with the positive control. The effects of the chloroform fraction at $3 \mathrm{~h}$ of induction were lower compared with its effects in the 1 st and 2 nd hours. The same trend was noted following $4 \mathrm{~h}$ of induction (Fig. 1D).

Wound contraction. As presented in Fig. 2 and Table I, the percentage of wound contraction in animals treated with the plant extract was higher compared with the corresponding percentage of contraction induced by the standard drug on measurement days 3-18; however, this difference was not statistically significant. On day 21 post-wounding, the two treatments induced complete closure. 
A

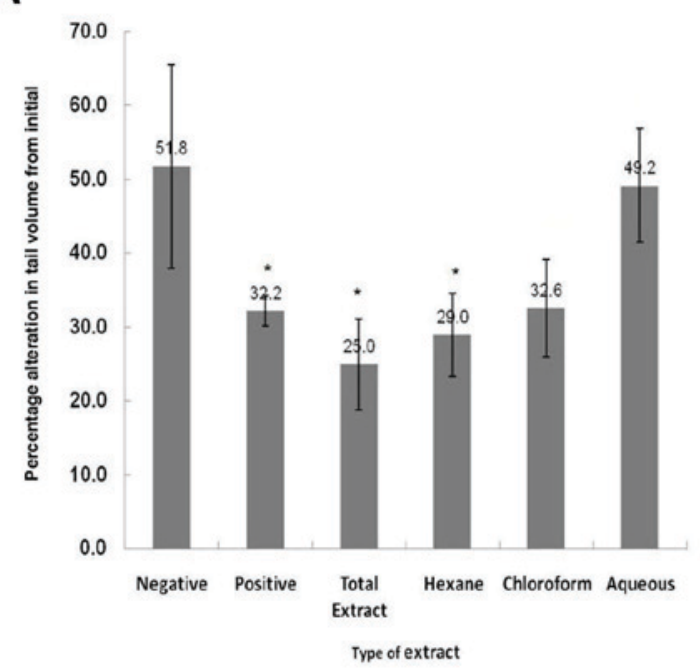

C

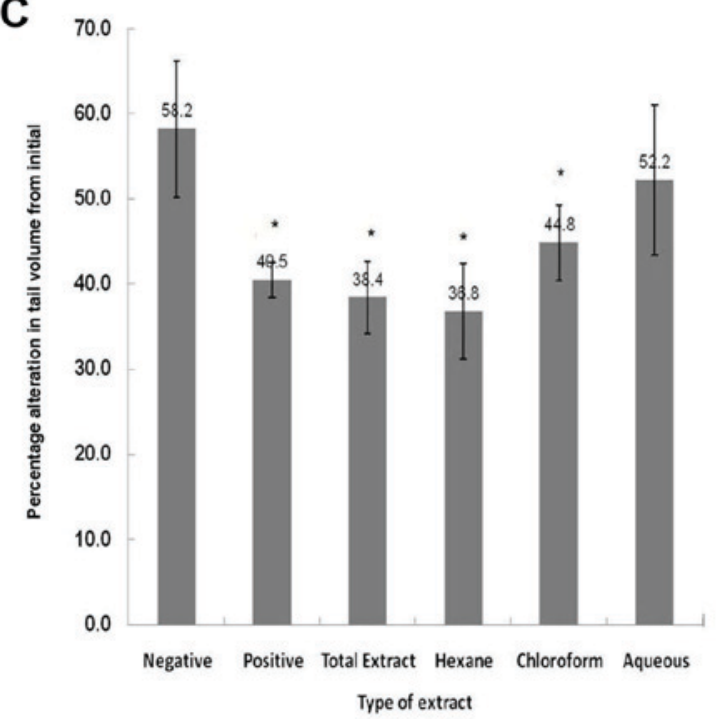

B 80.0

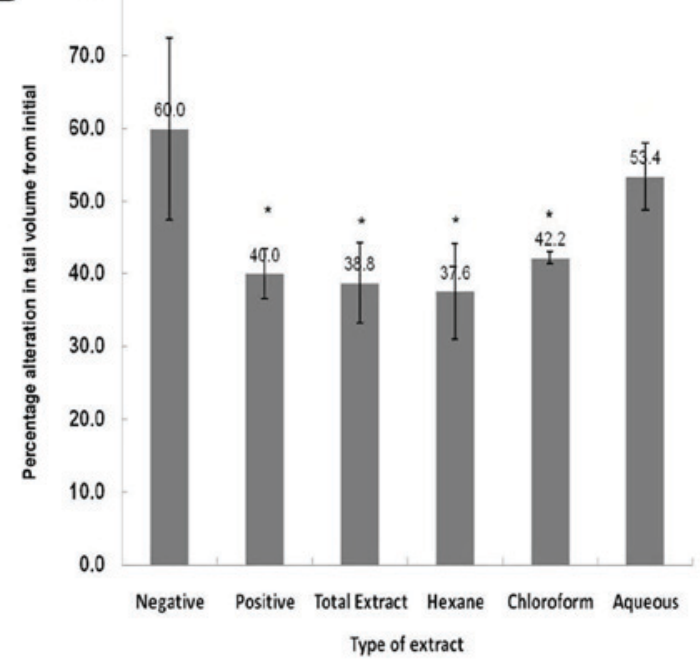

D

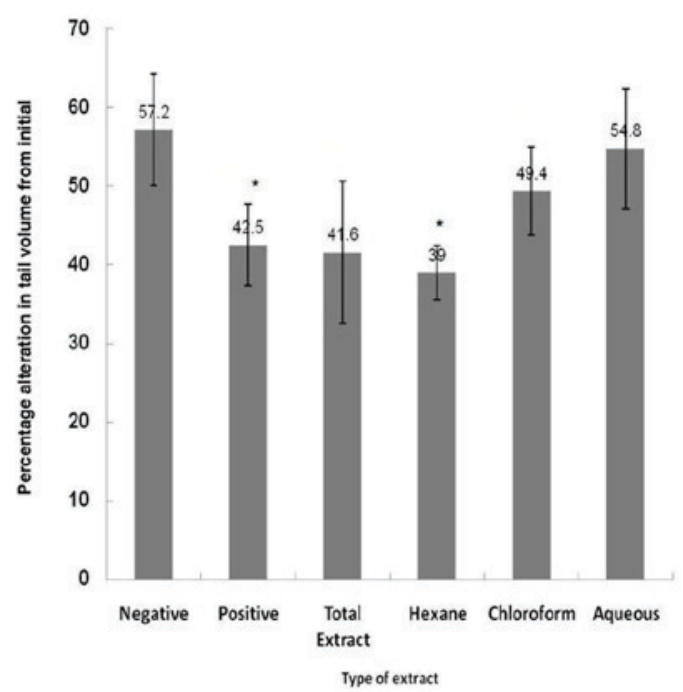

Figure 1. Effect of different fractions of Huernia Sp. Nov. aff. Boleana on mouse tail volume induced by formalin at (A) 1, (B) 2, (C) 3 and (D) 4 h. $\mathrm{n}=3$. ${ }^{*} \mathrm{P}<0.05$ vs. negative control.

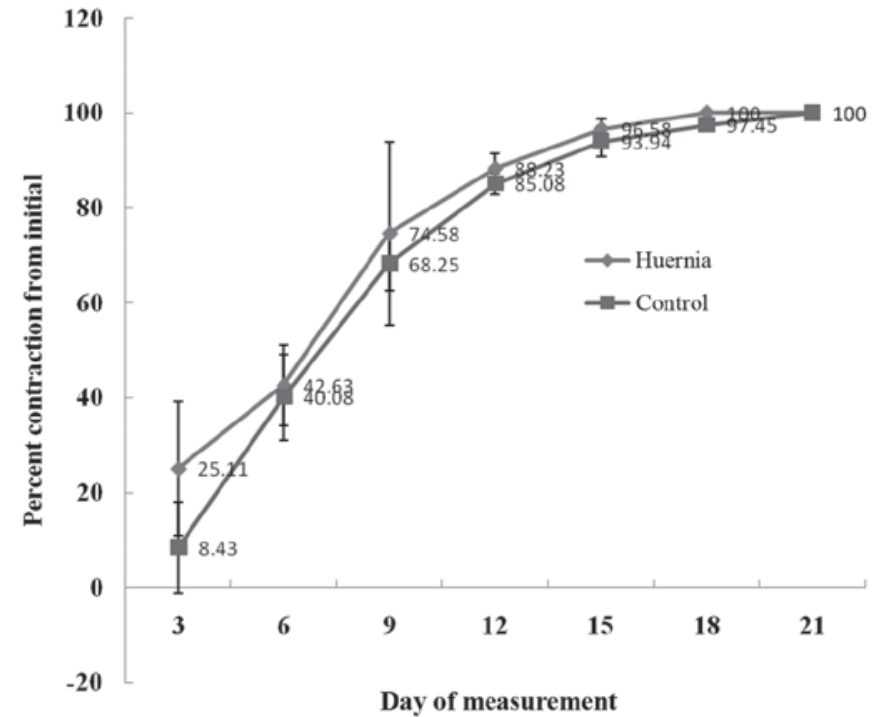

Figure 2. Effect of topical application of total extract of Huernia Sp. Nov. aff. Boleana on percentage wound contraction in rats.
Histological study. Staining of sections with H\&E revealed that, on day 7 post-wound injury, animals treated with the plant extract and with sulphadiazine exhibited a similar inflammatory response (Table II), and the difference was not statistically significant between the two treatments. The analysis of the day 7 sections demonstrated an increasing zone of inflammation in the early phases following injury. On day 14 , animals treated with the plant extract exhibited fewer alterations in the inflammatory response, while those administered the standard drug demonstrated a marked alteration compared with day 7 of the same group (Table II). On day 21, the inflammatory response induced by the two treatments significantly decreased compared with day 7 . The same trend was noted for animals treated with sulphadiazine; however, no significant differences were noted between the two treatments on day 21 .

Angiogenesis. As presented in Table II, on day 7 post injury, angiogenesis in the two treatment groups was almost complete, and no significant difference was observed between animals receiving the plant extract and those treated with the standard 
Table I. Multiple comparisons for percentage wound healing contraction in rats treated with sulphadiazine and total extract of Huernia Sp. Nov. aff. Boleana.

\begin{tabular}{|c|c|c|c|c|c|c|}
\hline \multirow[b]{2}{*}{ Day } & \multicolumn{2}{|c|}{$\%$ Wound healing contraction } & \multirow[b]{2}{*}{ Mean difference } & \multirow[b]{2}{*}{ P-value } & \multicolumn{2}{|c|}{$95 \%$ confidence interval } \\
\hline & Group & Group & & & Upper bound & Lower bound \\
\hline 3 & Control & Huernia Sp. Nov. aff. Boleana & -16.678 & 0.073 & -34.371 & 1.014 \\
\hline 6 & Control & Huernia Sp. Nov. aff. Boleana & -4.543 & 0.898 & -19.261 & 10.173 \\
\hline 9 & Control & Huernia Sp. Nov. aff. Boleana & -16.725 & 0.308 & -42.001 & 8.549 \\
\hline 12 & Control & Huernia Sp. Nov. aff. Boleana & -15.637 & 0.392 & -41.598 & 10.323 \\
\hline 15 & Control & Huernia Sp. Nov. aff. Boleana & -16.218 & 0.414 & -43.753 & 11.318 \\
\hline 18 & Control & Huernia Sp. Nov. aff. Boleana & -15.637 & 0.392 & -41.598 & 10.323 \\
\hline
\end{tabular}

Table II. Effects of topical application of $1 \%$ of Huernia Sp. Nov. aff. Boleana on inflammation, angiogenesis, fibroblasts, collagen and re-epithelization in round excision wound model in vivo.

\begin{tabular}{|c|c|c|}
\hline Date of specimen collection & Positive control & Huernia Sp. Nov. aff. Boleana \\
\hline \multicolumn{3}{|l|}{ Inflammation } \\
\hline Day 7 & $2.33 \pm 0.49$ & $2.58 \pm 0.15$ \\
\hline Day 14 & $1.00 \pm 0.00$ & $2.5 \pm 0.53^{\mathrm{a}}$ \\
\hline Day 21 & $0.75 \pm 0.71$ & $0.78 \pm 0.44$ \\
\hline \multicolumn{3}{|l|}{ Angiogenesis } \\
\hline Day 7 & $4.00 \pm 0.00$ & $3.83 \pm 0.39$ \\
\hline Day 14 & $3.75 \pm 0.71$ & $2.63 \pm 0.52^{\mathrm{a}}$ \\
\hline Day 21 & $1.63 \pm 0.74$ & $1.44 \pm 0.53$ \\
\hline \multicolumn{3}{|l|}{ Fibroblast } \\
\hline Day 7 & $4.00 \pm 0.00$ & $4.00 \pm 0.00$ \\
\hline Day 14 & $4.00 \pm 0.00$ & $4.00 \pm 0.00$ \\
\hline Day 21 & $2.00 \pm 0.00$ & $1.78 \pm 0.83$ \\
\hline \multicolumn{3}{|l|}{ Collagen } \\
\hline Day 7 & $1.42 \pm 0.51$ & $2.08 \pm 0.67$ \\
\hline Day 14 & $3.50 \pm 0.53$ & $2.88 \pm 0.35$ \\
\hline Day 21 & $4.00 \pm 0.00$ & $3.78 \pm 0.44$ \\
\hline \multicolumn{3}{|l|}{ Epithelization } \\
\hline Day 7 & $0.00 \pm 0.00$ & $0.67 \pm 0.98$ \\
\hline Day 14 & $2.00 \pm 0.00$ & $2.00 \pm 0.00$ \\
\hline Day 21 & $2.00 \pm 0.00$ & $1.89 \pm 0.33$ \\
\hline
\end{tabular}

For inflammation, angiogenesis, fibroblast and collagen: 0 , Absent; 1 , occasionally present; 2 , scattered in the field; 3, abundant; 4, confluent. For epithelization: 0, Absent; 1, presence of one layer; 2, presence of more than one layer. ${ }^{a} \mathrm{P}<0.05$ vs. the respective control group.

drug. In plant-treated animals, the formation of new blood vessels decreased as time progressed. Angiogenesis decreased from $3.83 \pm 0.39$ on day 7 to $2.63 \pm 0.52$ on day 14 , and to $1.44 \pm 0.53$ on day 21 post-injury (Table II). On day 21, a non-significant difference in the level of angiogenesis was observed between treatments. This suggested that the plant may have exhibited almost the same effect on wound angiogenesis as sulphadiazine.

Fibroblasts. Histological analysis indicated marked fibroblast proliferation, particularly on days 7 and 14 post-wounding in both treatments (Table II; Fig. 3). The degree of fibroblast proliferation was the same for both treatments, and no statistically significant differences were noted on the 7 th and 14 th days post-wounding. On day 21 , the extent of fibroblast proliferation was decreased by $\sim 50 \%$ in each treatment group. Fibroblasts in the treated group were not statistically different compared with the control group (Table II; Fig. 3Ca and b).

Collagen. On day 21 post-wounding, the results of the present study demonstrated that topical application of the plant extract resulted in increased collagen content. The amount of collagen in the extract-treated group was almost the same as 


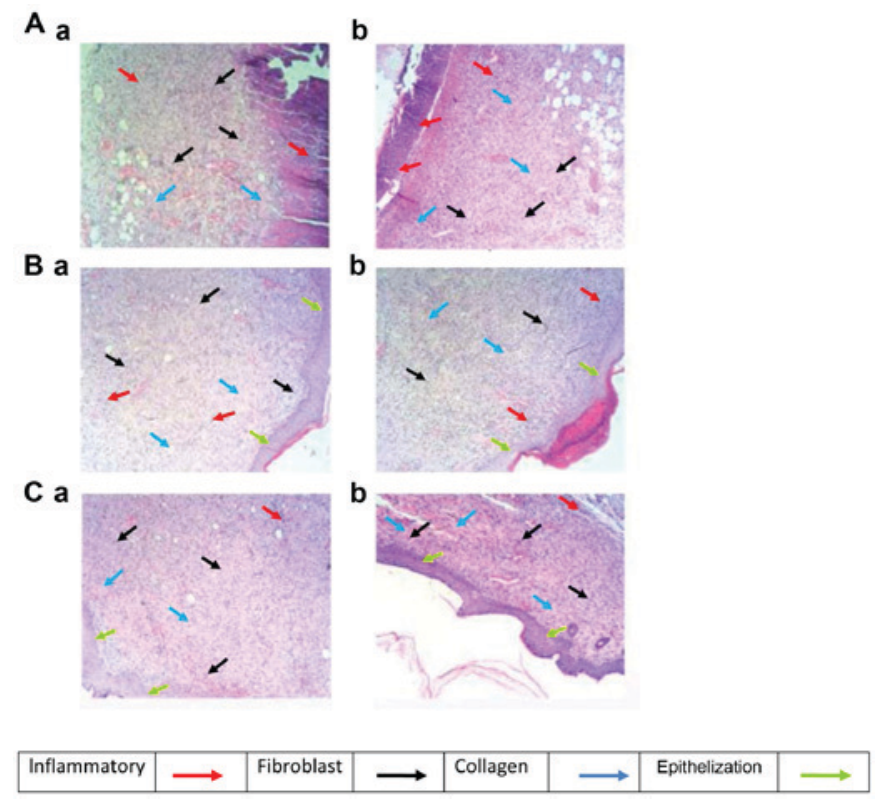

Figure 3. Histological observation (magnification, x100) of hematoxylin and eosin-stained sections of animals treated with $1 \%$ sulphadiazine and $1 \%$ methanol extract of Huernia Sp. Nov. aff. Boleana. (Aa) Animals treated with sulphadiazine on day 7 ; $(\mathrm{Ab})$ animals treated with the plant extract on day 7 post-treatment; $(\mathrm{Ba})$ rats treated with sulphadiazine on day 14; (Bb) corresponding animals in the experimental group; $(\mathrm{Ca})$ animals that received sulphadiazine on day $21 ;(\mathrm{Cb})$ animals that received the plant extract on day 21 post-treatment.

in the sulphadiazine group (3.78 vs. 4.0; Table II), although non-significant differences were observed between the treatment and the control groups.

Re-epithelization. A high degree of re-epithelization of the wounds was noted in animals treated with the plant extract on day 14 post-injury which was similar to the control (Table II; Fig. 3Ba and Bb). Furthermore, analysis of the sections on the 14th and 21st days demonstrated complete epithelization with well-formed and differentiated epithelial tissues (Table II; Fig. 3Bb-Cb).

Inhibition of B16-F10 melanoma cells migration following treatment with plant extract. Fig. 4 presents the percentage migration inhibition of B16-F10 melanoma cells following 12 and $24 \mathrm{~h}$ of treatment with 100 and $200 \mu \mathrm{g} / \mathrm{ml}$ methanol extract of Huernia Sp. Nov. aff. Boleana. The percentages of inhibition following 12-h treatments were 63.93 and $79.56 \%$ at concentrations of 100 and $200 \mu \mathrm{g} / \mathrm{ml}$, respectively (Figs. 4 and 5). However, no significant difference was noted between the two concentrations following $12 \mathrm{~h}$ of treatment. At $24 \mathrm{~h}$, cells treated with DMSO exhibited almost complete wound closure. Additionally, the extract induced percentages of migration inhibition of 36.05 and $84.08 \%$ at a concentration of 100 and $200 \mu \mathrm{g} / \mathrm{ml}$, respectively (Figs. 4 and 5). Unlike the results measured following $12 \mathrm{~h}$, the percentage of inhibitory cell migration $(84.08 \%)$ of cells treated with the higher concentration $(200 \mu \mathrm{g} / \mathrm{ml})$ of the plant extract was significantly increased compared with those treated with $100 \mu \mathrm{g} / \mathrm{ml}$, following $24 \mathrm{~h}$ of treatment $(\mathrm{P}<0.05)$. This indicated that the inhibition of cell migration may be dose-dependent. In addition, the results of

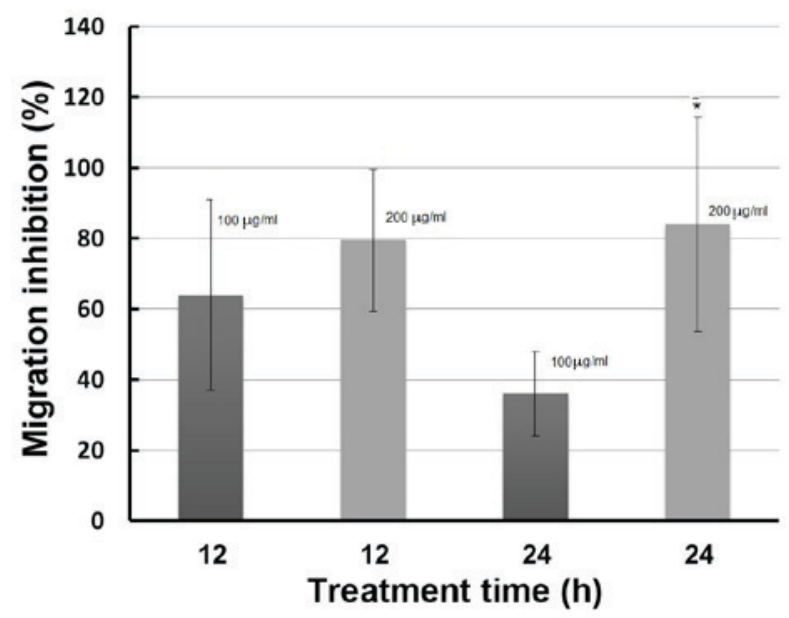

Figure 4. Effects of 100 and $200 \mu \mathrm{g} / \mathrm{ml}$ methanol extract of Huernia Sp. Nov. aff. Boleana on in vitro migration inhibition of B16-F10 cells. ${ }^{*} \mathrm{P}<0.05$ vs. treatment with $100 \mu \mathrm{g} / \mathrm{ml}$ at $24 \mathrm{~h}$.

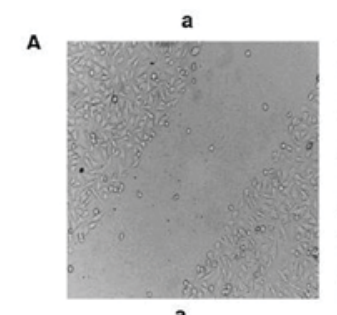

B
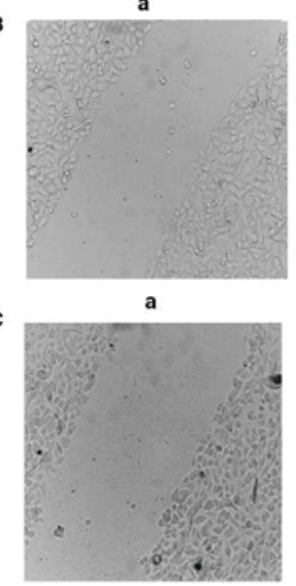

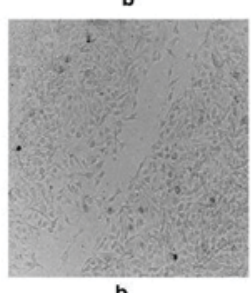

b

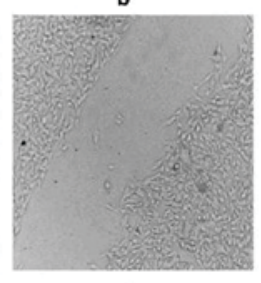

b

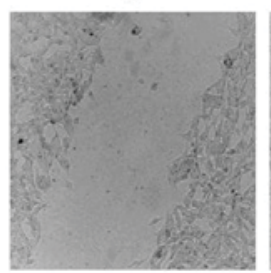

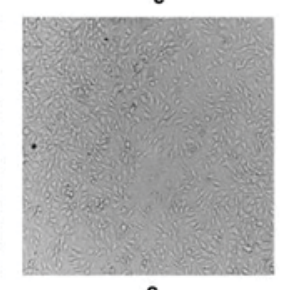

c

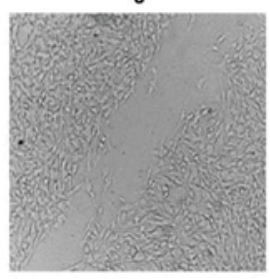

c

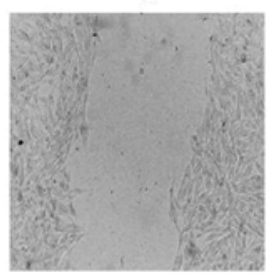

Figure 5. Effects of 100 and $200 \mu \mathrm{g} / \mathrm{ml}$ methanol extract of Huernia Sp. Nov. aff. Boleana on in vitro migration inhibition of melanoma cells (B16-F10; magnification, $\mathrm{x} 10)$. Images were captured at 0,12 , and $24 \mathrm{~h}$ via an in vitro scratch method. (Aa) Cells treated with DMSO at $0 \mathrm{~h}$; (Ab) cells treated with DMSO at $12 \mathrm{~h}$; (Ac) cells treated with DMSO at $24 \mathrm{~h}$; (Ba) cells treated with $100 \mu \mathrm{g} / \mathrm{ml}$ ethanol extract at $0 \mathrm{~h}$; (Bb) cells treated with $100 \mu \mathrm{g} / \mathrm{ml}$ ethanol extract at $12 \mathrm{~h}$; (Bc) cells treated with $100 \mu \mathrm{g} / \mathrm{ml}$ ethanol extract at $24 \mathrm{~h}$; (Ca) cells treated with $200 \mu \mathrm{g} / \mathrm{ml}$ ethanol extract at $0 \mathrm{~h}$; $(\mathrm{Cb})$ cells treated with $200 \mu \mathrm{g} / \mathrm{ml}$ ethanol extract at $12 \mathrm{~h}$; (Cc) cells treated with $200 \mu \mathrm{g} / \mathrm{ml}$ ethanol extract at $24 \mathrm{~h}$. DMSO, dimethyl sulfoxide.

the present study revealed that the duration of treatment (12 or $24 \mathrm{~h}$ ) had a non-significant effect on the percentage inhibition of cell migration, since non-significant differences were observed following 12 and $24 \mathrm{~h}$ for cells treated with the low concentration $(100 \mu \mathrm{g} / \mathrm{ml})$ of the plant extract. The same trend was noted for the cells treated with $200 \mu \mathrm{g} / \mathrm{ml}$ plant extract (Figs. 4 and 5). 


\section{Discussion}

The marked anti-inflammatory activity which was noted for the TE, hexane and chloroform fractions was notable, as the relatively non-polar fractions (hexane and chloroform) exhibit enhanced absorption via the cell membranes (8). Amoo et al (9) reported that petroleum ether and dichloromethane extracts of Huernia hystrix demonstrated good anti-inflammatory activity (>70\%) using cyclooxygenase (COX)-1 and COX-2 tests. Additionally, the anti-inflammatory activities noted by Amoo et al (9) may be explained, in part, by the presence of biologically active constituents, namely iridoids, phenols and flavonoids. The ethanol fraction of Pergularia daemia (Asclepiadaceae) was demonstrated to considerably decrease carrageen an-induced edema following $2 \mathrm{~h}$ at a dose of $100 \mathrm{mg} / \mathrm{kg}$, while the ethanol extract of Carissa carandas (Apocynaceae) exhibited marked levels of inhibition at the same dose $(100 \mathrm{mg} / \mathrm{kg})$ following $2 \mathrm{~h}$ (9). To the best of our knowledge, the present study was the first to investigate the anti-inflammatory effects of this novel plant species (Huernia Sp.Nov. aff. Boleana); however, the exact mechanism through which this plant may act as an anti-inflammatory agent was not revealed. The present study indicated the anti-inflammatory action of various fractions of this novel plant species, particularly the lipophilic fractions, although it offered little information concerning the mechanism of action (inhibition of the release of histamine and serotonin, orinhibition of COX-1 and COX-2). Thus, further study is recommended to investigate the anti-inflammatory mechanism. The extract exhibited a similar inhibitory influence at the early stage (within $1 \mathrm{~h}$ ) and the late stage (3-5 h) of inflammation. This contradicts the findings in the carrageenan-induced edema model, which are hypothesized to be bi-phasic (11). During the first phase, early mediators (histamine and serotonin) of inflammation are released, while in the late phase pro inflammatory mediators (particularly prostaglandins) are released (11). Sofidiyaa et al (11) reported that the ethanol extract of Alafia barteriOliv. (Apocynaceae) demonstrated a moderate inhibitory influence in the early stage, although it considerably inhibited carrageenan-induced edema during the late stage of inflammation. The impact of extract of Alafia barteri Oliv. May be due to the inhibition of pro inflammatory mediators released during acute inflammation, particularly prostaglandins. Similarly, Bhaskar and Balakrishnan (10) revealed that the inhibitory effect of Pergularia daemia (Asclepiadaceae), in addition to Carissa carandas (Apocynaceae), may be attributed to the inhibition of prostaglandin synthesis (i.e. inhibition of COX). Fikru et al (12) reported that the methanol extract of Achyranthes aspera L. (Amarenthaceae) markedly increased the percentage of wound contraction initiating from the 9 th day post-treatment; complete wound repair was noted in animals treated with this plant extract on day 21. Topical application of a curcumin formulation (20\%) and sulphadiazine notably increased the percentage of wound repair compared with the control group (13).

Infiltration of neutrophils and macrophages distinguish the inflammatory stages of repair; these leukocytes produce free angiogenic growth factors, in addition to pro inflammatory cytokines, that direct the recruitment of inflammatory factors and endothelial tissues to the site of injury (5). Idrusa et al (7) reported that, on day 3 following treatment with aqueous extract of Centella asiatica, infiltration and aggregation of polymorphonuclear and mononuclear cells was noted deep in the injured tissues, and on the exterior of the wound in all treatments. Similar results were reported by Fikru et al (12) using methanol extract of Achyranthes aspera L. (Amarenthacea). Thus, it may be concluded that the TE of Huernia Sp. Nov. aff. Boleana enhanced wound healing by inhibiting the inflammatory response. By decreasing the inflammatory response, the damaged skin tissues may readily enter the later phases of wound healing, in particular tissue formation and remodeling. The present study did not investigate mechanism of action by which the tested plant modulated inflammation. Thus, further study is recommended to investigate the mode of action of this plant. It is recommended to investigate the effects of this plant on two cytokines, tumor necrosis factor- $\alpha$ and interleukin-1. These two cytokines serve a crucial role in the inflammatory response regulation (4).

Normal tissue function requires a sufficient supply of oxygen via blood vessels. Understanding angiogenesis (the formation of new blood vessels) is a challenging aim, as it is crucial to numerous physiological and pathological processes. Reinstating the flow of blood to injured tissues is a requirement for a successful repair process. During granulation, tissue formation-activated macrophages, endothelial cells and fibroblasts create a functional unit crucial for effective angiogenesis (5). The endothelial cells activated by cytokines in the pre-existing vessels begin to infiltrate the wound site (provisional extracellular matrix) (14). Idrusa et al (7) reported that on day 21 following treatment with Centella asiatica, a significant degree of neovascularization was noted. While the present study indicated a significant degree of angiogenesis on day 7 for the two treatments, Krausz et al (15) demonstrated that curcumin-encapsulated nanoparticles prompted a higher degree of neovascularization in wounded tissues compared with other treatments. On day 21 post-treatment, 5 and $10 \%$ Achyranthes aspera L. (Amarenthaceae) revealed high degrees of angiogenesis (12).

Fibroblasts serve a central role in the wound healing process and are attracted to the injured tissues site by numerous growth factors, including platelet derived growth factor and transforming growth factor- $\beta$ (6). Fibroblasts attack the provisional extracellular matrix, proliferate, produce extracellular matrix components and differentiate into contractile myofibroblasts (5). Fibroblast migration into the wounded area is crucial for the formation of granular tissues, collagen synthesis and deposition (4). The results of the present study correspond with those of Idrusa et al (7), which demonstrated considerable proliferation of fibroblasts in animals treated with Centella asiatica extract, and were additionally consistent with the findings of Fikru et al (12), which reported marked proliferation of fibroblasts within the dermal layer in animals treated with 5 and $10 \%$ extract of Achyranthes aspera $L$.

Improved wound repair responses in the extract-treated animals may be attributed to an increase in fibroblast proliferation, which is involved in collagen synthesis. Collagen is the predominant protein of the extracellular matrix of the skin. It constitutes $70-80 \%$ of the skin and serves a central role in homeostasis. The strength and integrity of the wound matrix are provided by collagen (14). The ultimate goal of 
wound healing is the creation of scar tissue; thus, sufficient collagen creation and deposition at the site of the wound is required for wound healing (4). When an adequate level of collagen is synthesized into the granulation tissues, wound contraction is initiated via the action of myofibroblasts. This course of action attracts the margins of a wound closer to each other, therefore decreasing the injured area and expediting the wound closure (14). It may be concluded that the TE of the plant promoted wound repair via the enhancement of collagen synthesis. Similar results were reported by Idrusa et al (7) using Centella asiatica extract. This conclusion is also consistent with findings of Fikru et al (12). However, skin sections were not stained with Masson's Trichrome in the present study, thus, studying the degree of collagen deposition in healed tissues was not possible.

Analysis of the day 14 and 21 sections demonstrated complete epithelization with well-formed and differentiated epithelial tissues, which was consistent with the findings of Chereddy et al (16), revealing that curcumin-loaded nanoparticles resulted in complete epithelization on day 10 post-wounding. Similarly, Fikru et al (12) demonstrated that the extract of Achyranthesaspera L. exhibited a positive impact on the degree of re-epithelization. Krausz et al (15) reported that curcumin and curcumin-loaded nanoparticle-treated groups exhibited accelerated maturation of the epidermis and dermis.

A cell migration assay was used in the present study to investigate effects of the plant extract on wound healing in vitro, wherein the cells on the edge of 'scratch' may migrate in both directions in order to close the newly formed gap 'scratch'. This migration may continue until the establishment of new cell to cell contact. The migratory ability of the cells treated with DMSO was not compromised, as the distance between both sides of the scratch wound was almost completely closed at $24 \mathrm{~h}$ in the present study.

In conclusion, the anti-inflammatory effects (as indicated by the percentage alterations in tail size) of the TE, hexane and chloroform fractions were better or equivalent compared with the effect of the positive control. The lowest efficacy was noted in animals treated with the aqueous fraction of the plant. The results of the present study revealed that the relatively non-polar fractions (hexane and chloroform) exhibited higher anti-inflammatory activities compared with the aqueous fraction. The percentage wound contraction induced by the plant extract was higher compared with the corresponding percentage contraction of the standard drug (sulphadiazine) on all measurement days. The present study indicated that this novel plant enhanced wound repair via inhibition of the inflammatory response, promotion of fibroblast proliferation, stimulation of collagen synthesis and enhancement of re-epithelization. The in vitro scratch test indicated the inhibitory effects of this plant on melanoma cell (B16-F10) migration in a dose-dependent manner. The higher concentration $(200 \mu \mathrm{g} / \mathrm{ml})$ exhibited significant cell migration inhibition following $24 \mathrm{~h}$ of treatment compared with the lower concentration $(100 \mu \mathrm{g} / \mathrm{ml})$.

\section{Acknowledgements}

Identification of the plant was performed by Dr. Yassin M. Al-Sodany from the Department of Botany, College of Science, Taif University, KSA.

\section{Funding}

No funding was received.

\section{Availability of data and materials}

The analyzed data sets generated during the study are available from the corresponding author on reasonable request.

\section{Authors' contributions}

FH planned, designed and conducted the present study. AE performed the wound healing experiments and data analysis. QA and IA planned and executed the in vitro scratch method to analyse melanoma cell migration; they also performed data analysis. AR conducted the anti-inflammatory, wound healing and histological studies, as well as data collection and analysis. $\mathrm{SA}, \mathrm{AbA}$ and $\mathrm{AhA}$ were involved in the collection of samples and conducting experiments. YG and JM aided in sample collection and the preparation of plant extracts. All authors contributed to writing and evaluating the manuscript.

\section{Ethics approval and consent to participate}

The present study was approved by the Medical Ethical Committee at the Department of Pharmacology and Toxicology, College of Pharmacy, Taif University (2017/TU/Pharmacy/01), and followed the ethical guidelines EEC999 (European Union, 1982).

\section{Consent for publication}

Not applicable.

\section{Competing interests}

The authors declare that they have no competing interests.

\section{References}

1. Alzahrani SO, Alwagdani AM, Alotaibi AM, Hamaidi GM, Al-Remawi M, Gouda YG and Mohamed KM: Study of the antidiabetic activity of Huernia Sp. Nov. aff. boleana growing in high altitude areas of southwest saudi arabia. Annals Biol Sci 3: 15-20, 2015.

2. Almehdar H, Abdallah HM, Osman AM and Abdel-Sattar EA: In vitro cytotoxic screening of selected Saudi medicinal plants. J Nat Med 66: 406-412, 2012.

3. Steinmeyer $\mathbf{J}$ and Konttinen YT: Oral treatment options for degenerative joint disease-presence and future. Adv Drug Deliv Rev 58: 168-211, 2006.

4. Akbik D, Ghadiri M, Chrzanowski W and Rohanizadeh R: Curcumin as a wound healing agent. Life Sci 116: 1-7, 2014.

5. Eming SA, Brachvogel B, Odorisio T and Koch M: Regulation of angiogenesis: Wound healing as a model. Prog Histochem Cyto 42: 115-170, 2007.

6. Enoch S, Grey JE and Harding KG: Recent advances and emerging treatments. BMJ 332: 962-965, 2006.

7. Ruszymah BH, Chowdhury SR, Manan NA, Fong OS, Adenan MI and Saim AB: Aqueous extract of centella asiatica promotes corneal epithelium wound healingin vitro. J Ethnopharmacol 140: 333-338, 2012.

8. Liang CC, Park AY and Guan JL: In vitro scratch assay: A convenient and inexpensive method for analysis of cell migration in vitro. Nat Protoc 2: 329-333, 2007. 
9. Amoo SO, Finnie JF and Van Staden J: Acetylcholinesterase inhibition, antioxidant, antiinflammatory, antimicrobial and phytochemical properties of huernia hystrix. Phytother Res 26: 639-645, 2012.

10. Bhaskar VH and Balakrishnan N: Analgesic, anti-inflammatory and antipyretic activities of Pergularia daemia and Carissa carandas. DARU 17: 168-174, 2009.

11. Sofidiyaa MO, Imeha E, Ezeania C, Aigbeb FR and Akindeleb AJ: Antinociceptive and anti-inflammatory activities of ethanolic extract of Alafia barteri. Rev Bras. Farmacogn 24: 348-354, 2014

12. Fikru A, Makonnen E, Eguale T, Debella A and Abie Mekonnen G: Evaluation of in vivo wound healing activity of methanol extract of achyranthes aspera L. J Ethnopharmacol 143: 469-474, 2012.

13. Durgaprasad S, Reetesh R, Hareesh K and Rajput R: Effect of a topical curcumin preparation (BIOCURCUMAX) on burn wound healing in rats. J Pharm Biomed Res 8: 1-3, 2011.
14. Koivisto L, Heino J, Häkkinen L and Larjava H: Integrins in wound healing. Adv Wound Care (New Rochelle) 3: 762-783, 2014.

15. Krausz AE, Adler BL, Cabral V, Navati M, Doerner J, Charafeddine RA, Chandra D, Liang H, Gunther L, Clendaniel A, et al: Curcumin-encapsulated nanoparticles as innovative antimicrobialand wound healing agent. Nanomedicine 11: 195-206, 2015.

16. Chereddy KK, Coco R, Memvanga PB, Ucakar B, Rieux AD, Vandermeulen G and Préat V: Combined effect of PLGA and curcumin on wound healing activity. J Cont Rel 171: 208-215, 2013. 